\title{
Determine the Effect of Polymorphisms of and IL23R Genes on in Psoriasis in Babylon Province
}

\author{
Dheyaa B. Mohammad ${ }^{1}$, Thana M. Alswedi², Wisam AliAwadh ${ }^{2}$ \\ ${ }^{1}$ Lecturer, ${ }^{2}$ Assiss. Prof., Faculty of Medicine, Babylon University, Iraq
}

\begin{abstract}
Background: IL23R Polymorphisms appear to be engaged with several different types of autoimmune diseases such as psoriasis.

Aim: We investigated the association of the Arg381Gln (R381Q) polymorphism in the IL23R gene with psoriasis risk in Babylon province.

Methodology: The IL23R-gene variation Arg381Gln (R381Q) was performed using the programmable thermal cycler gradient PCR system. We investigated the association of IL23R gene variants with different clinic pathological features of psoriasispatients.

Results: The allelic frequency of IL-23R Arg381Gln (R381Q) (rs11209026) gene showed that the frequency of AA genotype in patients with Psoriasis was more than in the control group (13 vs $8 \%)(\mathrm{OR}=2.222$, CI 95\% (0.476-10.357). In addition, this study suggests there is a statistical difference ( $\mathrm{P}$-valu $>0.05)$ between $(\mathrm{AG})$ and $(\mathrm{AA})(\mathrm{P}$-value $=0.033),(\mathrm{AG})$ and $(\mathrm{GG})(\mathrm{P}$-value $=0.012)$ genotypes in patients group compared to controls. The results also showed that the frequency of $(\mathrm{G})$ Arg allele was $(0.6)(0.62)$ in patients and control group respectively, and found no significant difference between (A) Gln and (G) Arg alleles in patients and controls $(\mathrm{OR}=0.754)$, CI 95\% (0.42-1.22).

Conclusion: Our results showed no significant association of the IL-23R Arg381Gln (R381Q) (rs11209026) polymorphism with psoriasis patients susceptibility in Babylon province. The IL-23R Arg381Gln heterozygoteno significantly increases the risk and can't be useful as a predisposing genetic marker.
\end{abstract}

Keywords: Psoriasis, polymorphism, IL-23R Arg381Gln, Health; skin.

\section{Introduction}

Psoriasis is an immune-mediated proliferative skin disorder and chronic inflammatory disease that predominantly involves the skin, nails, and joints that have a prevalence of $3 \%$ worldwide ${ }^{(1)}$. The disease happens in the different age groups with less than 10 years occurrences is rare (incidence 0.3-0.5), and

\section{Corresponding Author:}

\section{Dheyaa B. Mohammad}

Lecturer, Faculty of Medicine, Babylon University, Iraq e-mail: d1212d.basim@gmail.com greatly between $15-40$ years ${ }^{(2)}$. The main reason is still unknown, historically, psoriasis is considered a primary disorder of keratinocyte ${ }^{(3,4)}$. There is hyper-proliferation of keratinocytes and alteration in differentiation Genetic abnormality leads to keratinocytes hyper-proliferation which in turn, produces a defective skin barrier allowing the penetration of antigens which resulting in the immune response to that antigen $(\mathrm{Ag})^{(5)}$. Recently the genetic mapping of the MHC Class I show that region indicates that HLA-Cw6 itself is probable to be the functional variable predisposing to psoriasis, rather than sing for some other disease gene neighbor. This finding provides a molecular target for the explanation of the immunologic basis of psoriasis ${ }^{(6,7)}$. TNF- $\alpha$ (Tumor necrosis factor-alpha), IL-17 (interleukin 17), IL-6 is a group of inflammatory cytokines produced by human 
adipose tissue and plays a significant role in the begin of insulin resistance, dyslipidemia, D.M and finally cardiac disease in psoriatic patients (8). An adipose tissue macrophage is responsible for producing inflammatory cytokines $\alpha$-TNF, IL-6, 7, 8, 17, 18, 23 in response to adipose tissue inflammation, which leads to increasing the level of this cytokines, and resulting in endothelial cell damage and atherosclerotic plaque additionally to initiation of psoriasis ${ }^{(9)}$. This study aimed to identify the influence of IL23R gene rs11209026 SNPs variant on the susceptibility of developing psoriasis.

\section{Materials and Method}

DNA Extraction: DNA was extracted by the procedure depending on the manufacture protocol and was detected by using the agarose gel electrophoresis technique.

\section{IL-23RArg381GIn (R381Q) (rs11209026)} genotyping: Amplification IL23R gene was done by polymerase chain reaction (PCR). Amplification was performed in a programmable thermal cycler gradient PCR system that allows amplification of test DNA only when the target allele is contained within the sample. PCR-restriction fragment length polymorphism was used to investigate the polymorphism (rs11209026, Arg381Gln, R381Q) in the IL-23 receptor (IL23R) gene in control and psoriasis patients involved in this study. Optimization of PCR-RFLP conditions was done by using:

The different volumes of primer $(1 \mu \mathrm{l}$, and 1.5 $\mu 1)$.Gradient annealing temperature and choosing the conditions that gave the best result.

A master premix of Promega ${ }^{\circledR}$ was used as mentioned with PCR conditions.Master premix components Top DNA polymerase $1 \mathrm{U} / \mu \mathrm{l})$, Each: $\operatorname{dNTP}(250 \mathrm{mM})$, Tris- $\mathrm{HCl}$ (pH 9.0) $10 \mathrm{mM}, \mathrm{KCl}(30 \mathrm{mM}), \mathrm{MgCl} 2$ (1.5 $\mathrm{mM})$,Stabilizer and tracking dye.

\section{Amplification conditions of IL-23RArg381GIn} (R381Q) genotyping: The amplification conditions used were at $94 \mathrm{C}$ for 5 minutes followed by $94 \mathrm{C}$ for $1 \mathrm{~min}, 61$ $\mathrm{C}$ for $1 \mathrm{~min}, 72 \mathrm{C}$ for $1 \mathrm{~min}$ followed by the final extension at $72 \mathrm{C}$ for 5 minutes. The amplification products were separated by electrophoresis through $1.5 \%$ agarose gel stained with ethidium bromide and visualized on a UV transilluminator. Primers $\mathrm{F}$ and $\mathrm{R}$ flank the exon of the IL-23R Arg381Gln (R381Q)gene, resulting in a band of $508 \mathrm{bp}$ to act as a control for DNA quality and quantity.
Primers Fand R amplify a wild-type allele ( $G$ allele), generating a band of $288,103,82,35 \mathrm{bp}$, and primers $\mathrm{F}$ and $\mathrm{R}$ generate a band of $323,103,82 \mathrm{bp}$ from the mutant allele(A allele),.The best temperature was determined to be $58^{\circ} \mathrm{C}$ in the temperature range of $55^{\circ} \mathrm{C}$ to $63^{\circ} \mathrm{C}$ tested with a gradient PCR thermocycler. The annealing temperature was lowered from 60 to $58^{\circ} \mathrm{C}$ to favor the binding of both forward wild and reverse mutant primers that contain mismatches to the templates. The number of cycles was increased from 30 to 35 cycles, significantly enhancing the yields of all three PCR products. Together, these changes resulted in a more robust amplification of the mutant allele and a less competing reaction from the control, as shown by the relative intensities of the corresponding bands on agarose gel electrophoresis.

\section{Results}

The results of the present study showed that the frequency of $\mathrm{AA} \backslash \mathrm{Arg} / \mathrm{Arg}$ genotype/phenotype in patients with Psoriasis was more than in the control group $(13$ vs $8 \%)(\mathrm{OR}=2.222$, CI 95\% (0.476-10.357). In addition, this study suggests there is a statistical difference ( $\mathrm{P}$-valu $>0.05)$ between $(\mathrm{AG})(\mathrm{Arg} / \mathrm{Gln}$ and (AA) $\mathrm{Gln} / \mathrm{Gln}(\mathrm{P}$-value $=0.033),(\mathrm{AG}) \mathrm{Arg} / \mathrm{Gln}$ and (GG) Arg/Arg (P-value $=0.012$ ) genotypes/phenotype in patients group compared to controls. The results also showed that the frequency of (G) Arg allele was (0.6) (0.62) in patients and control group respectively, and found no significant difference between (A) Gln and (G) Arg alleles in patients and controls $(\mathrm{OR}=0.754)$, CI $95 \%(0.42-1.22)$. The rs 11209026 IL23R variant was a protective marker. Recent studies have shown that a functional single nucleotide polymorphism (SNP) (Arg381Gln; R381Q; rs11209026; 1142 G wild-type A reduced function) in the IL-23R gene (in exon 9) led to decreased IL-23- dependent IL-17 production (Guan et al. 2012). The disease-protective R381Q IL-23R may result in a loss of function, in primary human $\mathrm{CD} 4+$ and CD8+ T-cells, leading to decreases in IL-23/TH17 pathway cytokine production.

Study Population: All demographic characteristics of the subjects are shown as follows a total of 45 psoriasis patients and the same number of gender-matched healthy control wereanalyzed. This research was confirmed by the Research ethics committee, University of Babylon college of medicine. Blood $(5 \mathrm{ml})$ samples were collected from participants in EDTA and gel tubes. 


\section{Discussion}

A survey by Di Meglio and Suggested that IL-23R RQ381 exerted its protective effects by attenuation of IL-23-induced TH17 functions (IL-17A production) without interfering with TH17 differentiation (10). Further, Sarin et al. 2011 showed that CD4 and CD8+ T-cells from healthy R381Q IL-23R carriers had decreased IL-23-dependent IL-17 and IL-22 production relative to WT (wild-type; G allele) cells Several mechanisms might contribute to these observations, including a reduced capacity of IL23RQ381 to activate STAT proteins due to an impaired association of JAK2 proteins with the cytoplasmic tail of the receptor ${ }^{(11)}$. As a result, R381Q CD8+ and TH17 CD4+ T-cells displayed decreased IL-23- and STAT3-dependent expansion, STAT3 phosphorylation, and STAT3 activation compared with WT cells . This SNP was also associated with a lower percentage of circulating TH17 and TC17 cells. Abdollahi et al. 2015reported that the number and activity of both circulating TH17 cells and in vitro (ex vivo)-differentiated TH17 cells did not differ between $\mathrm{G}$ and $\mathrm{A}$ allele carriers ${ }^{(12)}$. This finding supported the belief for a major role for IL23 in the generation of TH17 cell effector responses during tissue inflammation (rather than in systemic inflammation) and demonstrated the importance of IL-23 in mediating TH17 effector responses in humans. Those results also provided support for a critical role for the IL-23/IL-23R signaling in generating pathogenic TH17 responses. Further, those studies explained the protective role of R381Q in autoimmune disorders and further supported the hypothesis that blocking the IL-23 pathway could lead to improvements in hosts with autoimmune disorders like psoriasis ${ }^{(13)}$. Raymond et al. 2015 investigated another mechanism of function for this SNP. The results of that study showed the R381Q variant promoted the expression of a soluble IL-23R-encoding mRNA species. The R381Q polymorphism altered the IL-23R alphachain mRNA splicing and favored exon 9 skipping by reducing the binding of the splicing enhancer SF2. This enhanced expression of the D9 mRNA consequently diminished IL-23 signaling. Multiple splice forms of the human IL23R transcript exist and one, D9, encodes a soluble form of the receptor. Thus, a presence of an R381Q variant increases the expression of the soluble form of IL23R mRNA (which, in turn, then functions as a decoy receptor) and lowers the ability of a host to develop a TH17 phenotype upon IL-23 stimulation ${ }^{(14)}$. This study that we mention it agrees with our present study that patient or control that have (AA)Gln $\backslash$ Gln genotype $\backslash$ phenotype have $(\mathrm{OR}=2.222)$ chance possible disease occurrence and (GG)Arg/Arg genotype phenotype have (2.074) possible chance disease when we compare with the reference group (AG) Gln $\backslash$ Arg that consider a protective.In conclusion, our result showed no significant correlation with IL-23R Arg381Gln (R381Q) genepolymorphism with psoriasis susceptibility in the Babylon population. IL-23R Arg381Gln (R381Q) genein over dominant model there are no significant increases in the risk of psoriasis and it's can't be useful as a predisposing genetic marker for psoriasis.

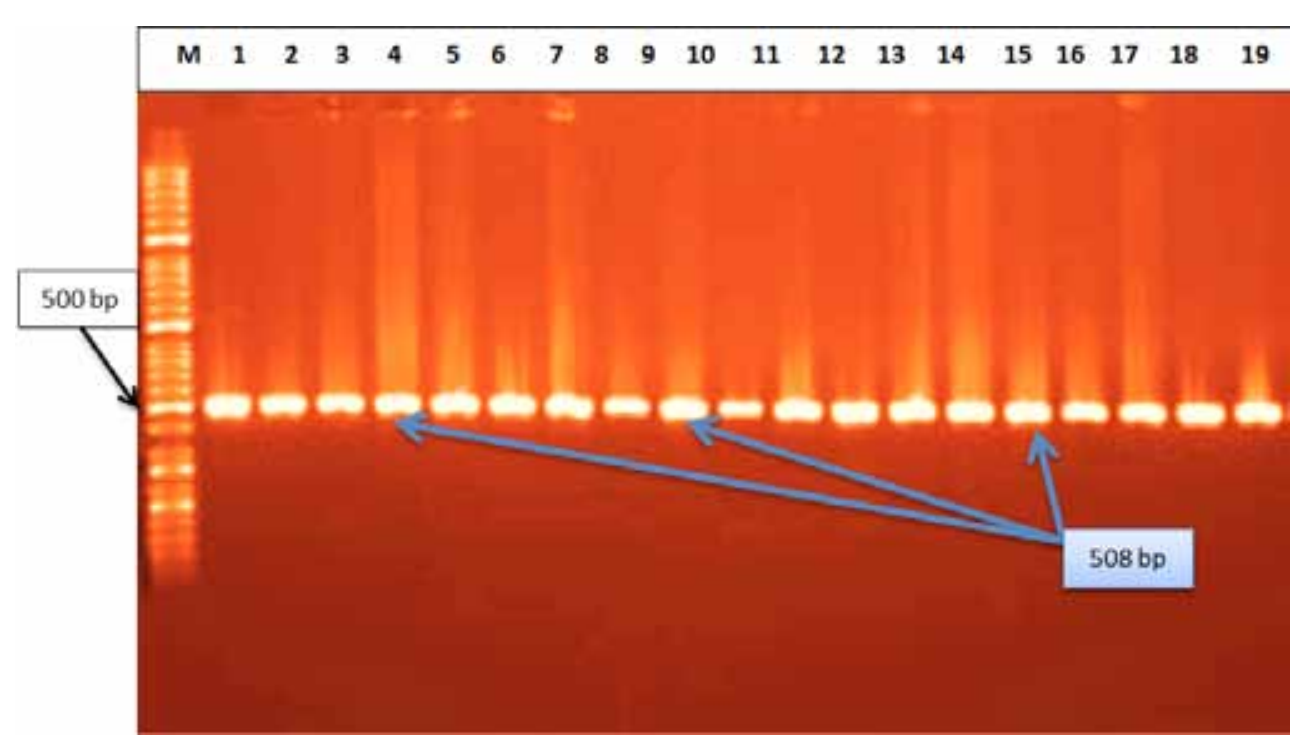

Figure (1): Amplification and PCR product (508bp) picture ofPCR products of the interleukin 23 (IL-23R) receptor on 1.5\% agarose. M= DNA Marker(ladder)(50 bp), (1 -19),508 bp PCR amplicons of IL-23R gene of patients group. 


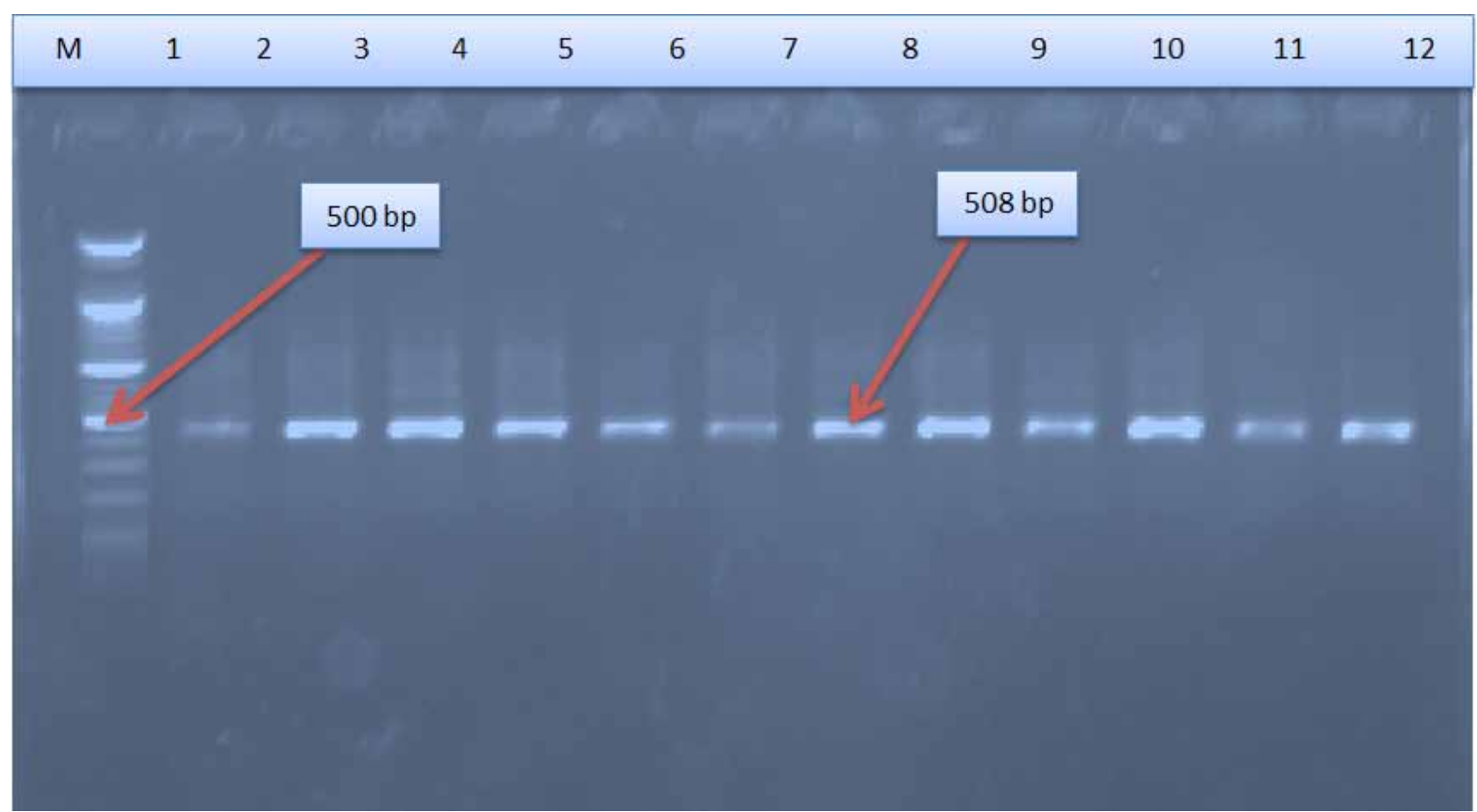

Figure (2): Amplification and PCR product (508bp) picture of PCR products of the interleukin 23 (IL-23R) receptor on 1.5\% agarose. M= DNA Marker(ladder) (50 bp), (1 -12),508 bp PCR amplicons of IL-23R geneof control group.

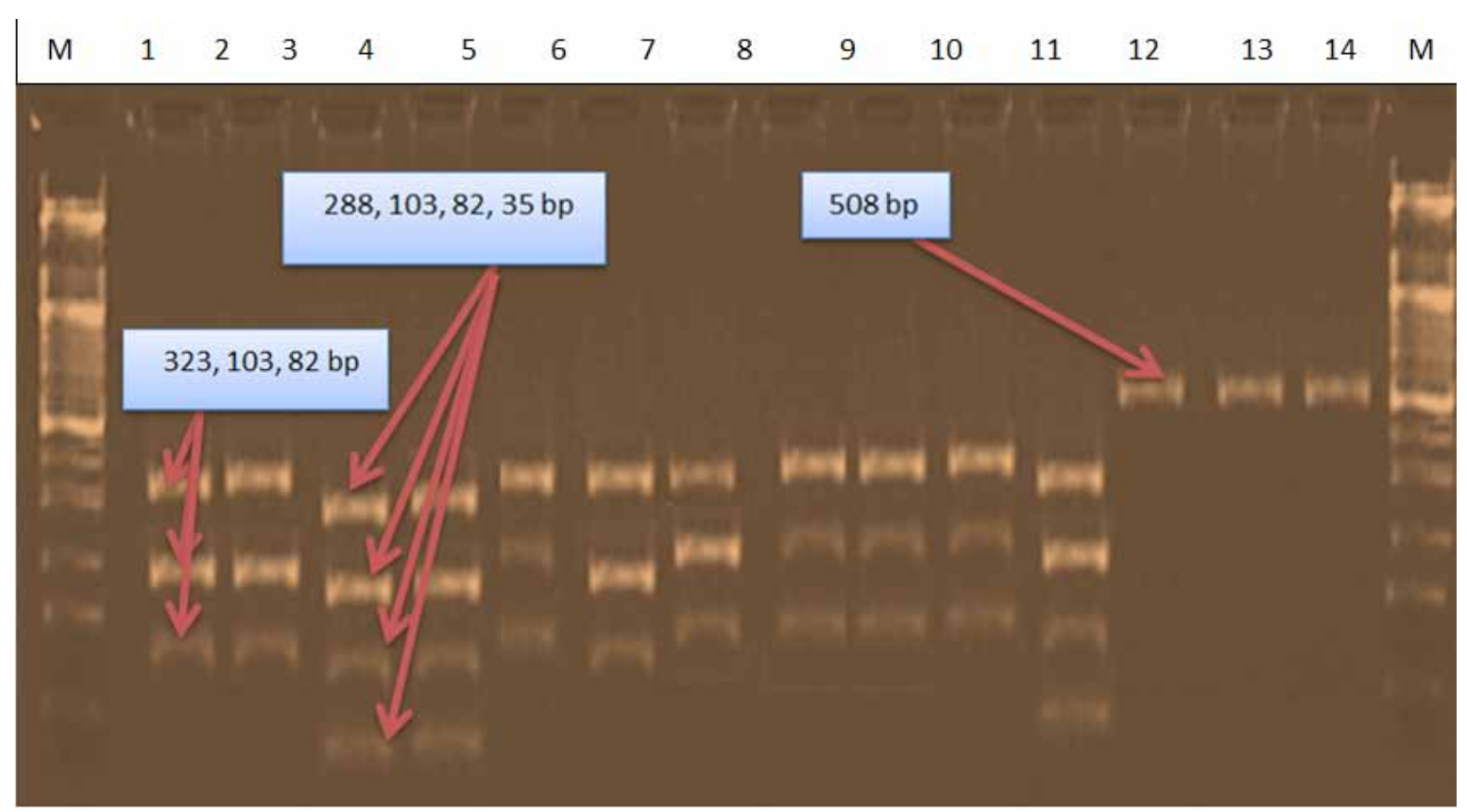

Figure (3): Electrophoretic picture (PAGE) representsrestriction fragment length polymorphism assay (PCR-RFLP) for rs11209026 IL-23R (G1142A) genotyping, where lane M is 50 bp DNA marker(ladder), lane $(1,2,5,6,7,8,9,10)(3$ bands)represent of mutant allele, lane $(3,4,11)(4$ bands)represent of wild-type allele, and lane $(12,13,14)$ (1 band)represent cases have both, normal and mutant allele.(PAGE: Polyaceylamide gel electrophoresis $6 \%)$. 
Table (1): The forward and reverse primers

\begin{tabular}{|l|c|c|}
\hline Primers & Sequence & References \\
\hline Forward primer & 5'-CTTTTCTGGCAGGGTCATTTTG-3' & 80 \\
\hline Reverse primer & 5'-AAGTTGTTTCCTGGGGTAGTTGTG-3' & \\
\hline
\end{tabular}

Table (2): Genotyping of IL-23R rs11209026 Arg381GIn (R381Q) polymorphism and allele frequency.

\begin{tabular}{|c|c|c|c|c|c|c|}
\hline \multirow{2}{*}{ Groups } & \multicolumn{3}{|c|}{ IL-23R Genotype (Arg381GIn) } & \multirow{2}{*}{ Total } & \multicolumn{2}{|c|}{ Allele frequency $(p+q=1)$} \\
\hline & $\mathbf{A A}$ & AG & GG & & $\mathbf{A}$ & G \\
\hline Control $\mathrm{N}=40$ & $3(8 \%)$ & $28(70 \%)$ & $9(22 \%)$ & 40 & $40 \%$ & $60 \%$ \\
\hline Patien $\mathrm{N}=40$ & $5(13 \%)$ & $21(52 \%)$ & $14(35 \%)$ & 40 & $38 \%$ & $62 \%$ \\
\hline Total & 8 & 49 & 23 & 80 & & \\
\hline$\left(\right.$ chi $^{2}$ Test $)$ p-value & NS & $\mathrm{S}$ & $\mathrm{S}$ & & & \\
\hline
\end{tabular}

Table (3): IL-23R rs11209026 Arg381GIn (R381Q) gene polymorphism characterization in patient and control groups

\begin{tabular}{|c|c|c|c|c|c|}
\hline Genotype & Patient & Control & Odd ratio & CI 95\% & p-value \\
\hline $\mathrm{AA}$ & $5(13 \%)$ & $3(8 \%)$ & $2.222 *$ & $0.476-10.357$ & 0.033 \\
\hline $\mathrm{AG}$ & $21(52 \%)$ & $28(70 \%)$ & \multicolumn{3}{|c|}{ Reference group } \\
\hline GG & $14(35 \%)$ & $9(22 \%)$ & $2.074 *$ & $0.754-5.687$ & 0.012 \\
\hline $\mathrm{A}$ & $40 \%$ & $38 \%$ & \multirow{2}{*}{0.754} & \multirow{2}{*}{$0.42-1.22$} & \multirow{2}{*}{0.771} \\
\hline $\mathrm{G}$ & $60 \%$ & $62 \%$ & & & \\
\hline
\end{tabular}

*: significant (p-value $<0.05)$

Ethical Clearance: The Research Ethical Committee at scientific research by ethical approval of both MOH and MOHSER in Iraq.

Conflict of Interest: None

Funding: Self-funding

\section{References}

1. Dogra S, Mahajan R. Psoriasis: Epidemiology, clinical features, co-morbidities, and clinical scoring. Indian Dermatol Online J. 2016;7(6):471.

2. Luk KMH, Tangpricha V, Chen SC. Vitamin D in Psoriasis. In: Vitamin D. Springer; 2016. p. 87-98.

3. Gupta S, Garg P, Gupta N. Dyslipidemia in psoriasis patients: a case-control study. Int J Res. 2019;5(1):101.

4. Lønnberg AS, Skov L. Co-morbidity in psoriasis: mechanisms and implications for treatment. Expert Rev Clin Immunol. 2017;13(1):27-34.

5. Yan K, Zhang Y, Han L, Huang Q, Zhang Z,
Fang X, et al. Safety and efficacy of methotrexate for Chinese adults with psoriasis with and without psoriatic arthritis. JAMA dermatology. 2019;155(3):327-34.

6. Yan K, Zhang Y, Han L, Huang Q, Zhang Z, Fang $\mathrm{X}$, et al. Investigation of psoriasis susceptibility loci in psoriatic arthritis and a generalized pustular psoriasis cohort. In: Journal of Investigative Dermatology Symposium Proceedings. Elsevier; 2018. p. S83-5.

7. Yan K, Zhang Y, Han L, Huang Q, Zhang Z, Fang $X$, et al. Toxico Pathological Evaluation of Tridax Procumbens in Laboratory Animal with Special Reference to Anti Inflammatory Effect in Rat and Mice. 2018;

8. Eberle FC, Brück J, Holstein J, Hirahara K, Ghoreschi K. Recent advances in understanding psoriasis. F1000 Research. 2016;5.

9. Ellulu MS, Patimah I, Khaza'ai H, Rahmat A, Abed Y. Obesity and inflammation: the linking 
mechanism and the complications. Arch Med Sci AMS. 2017;13(4):851.

10. Capon F, Di Meglio P, Szaub J, Prescott NJ, Dunster C, Baumber L, et al. Sequence variants in the genes for the interleukin-23 receptor (IL23R) and its ligand (IL12B) confer protection against psoriasis. Hum Genet. 2007;122(2):201-6.

11. Sarin $\mathrm{R}, \mathrm{Wu} X$, Abraham C. Inflammatory disease protective R381Q IL23 receptor polymorphism results in decreased primary $\mathrm{CD} 4+$ and $\mathrm{CD} 8+$ human T-cell functional responses. Proc Natl Acad Sci. 2011;108(23):9560-5.
12. Golovatyuk KP. Role of gene polymorphism of IL-4 and IL-17 in recurrent miscarriage, came in art cycles. Reprod Endocrinol. 2017;(33):26-31.

13. Abdollahi E, Tavasolian F, Momtazi-Borojeni AA, Samadi M, Rafatpanah H. Protective role of R381Q (rs11209026) polymorphism in IL-23R gene in immune-mediated diseases: A comprehensive review. J Immunotoxicol. 2016;13(3):286-300.

14. Raymond YY, Brazaitis J, Gallagher G. The human IL-23 receptor rs11209026 A allele promotes the expression of a soluble IL-23R-encoding mRNA species. J Immunol. 2015;194(3):1062-8. 